\title{
An efficiency assessment analysis of a modified gravitational Pelton-wheel turbine
}

\section{Raj Kumar Kapooria}

National Institute of Technology Kurukshetra, India and Faculty Mechanical Workshops Affiliated M. D. University Rohtak, India

\begin{abstract}
A Pelton-wheel impulse turbine is a hydro mechanical energy conversion device which converts gravitational energy of elevated water into mechanical work. This mechanical work is converted into electrical energy by means of running an electrical generator. The kinetic energy of the Water-jet is directed tangentially at the buckets of a Pelton-wheel. The Water-jet strikes on each bucket's convex profile splitter and get split into two halves. Each half is turned backwards, almost through $180^{\circ}$ relative to the bucket on a horizontal plane. Practically this angle may vary between $165^{\circ}$ to $170^{\circ}$. Normally all the jet energy is used in propelling the rim of the bucket wheel. Invariably some jet water misses the bucket and passes onto the tail race without doing any useful work. This hydro device is a good source of hydro-electrical energy conversion for a high water head. The present work in this research paper deals with some advanced modifications in the conventional Pelton-wheel so that it can be used for low-head and heavy-discharge applications. Both kinetic and potential energy of the water source is consumed by the runner wheel. Considerable gravitational effect of the water jet is exploited by means of some modifications in a conventional Peltonwheel. A comparatively heavy generator can be run by this modified Pelton-wheel turbine under lowhead and heavy-discharge conditions. The modified features provide enough promising opportunities to use this turbine for Mini and Micro hydro power plants.
\end{abstract}

Keywords: efficiency, gravitation, hydro, impulse, jet-propulsion, kinetic-head, Pelton-wheel efficiency, potential-head, torque, water head, water-jet

\section{Introduction}

Hydro-power is an ancient resource of green electricity. Water from the rivers, lakes, ponds and plants evaporates due to sunlight heating. This results in the rise of water vapour against the gravitational pull of the earth. In the atmosphere, it cools and condenses into drops of rain and snow, which falls on hills and mountains. A considerable amount of solar energy is still retained in the water in the form of gravitational potential energy. Therefore, solar energy is the ultimate source of hydro energy which basically represents stored gravitational energy. It is understood that water continuously flows on the earth surface to reach the sea. This happens because of the spherical shape of the earth that tenders a natural gravitational pull on surface water. The amount of stored hydro energy is directly proportional to the height and amount of the water above sea level. A turbine is the mechanical device which consumes the hydro energy of an elevated water level by means of pressure energy (in the case of a reaction turbine) or by means of kinetic energy (in the case of an impulse turbine). The hydro energy consumed by a turbine is passed to the electrical generator shaft in the form of mechanical energy. A Pelton-wheel is a tangential flow free-jet-impulse turbine named after an American engineer, Lesser Pelton. It is simple, robust and the only hydraulic turbine which operates efficiently on high heads in excess of $450 \mathrm{~m}$. The working pressure in this turbine remains atmospheric only. It possesses simple construction and smooth running features with good performance characters.

\section{Working principal and hydraulic efficiency of a conventional Pelton-wheel turbine}

The water from the reservoir flows through a penstock which contains a nozzle at the outlet. The nozzle increases the kinetic energy of the penstock water. At the outlet this nozzle produces a Water-jet. This Water-jet strikes on the buckets (Vanes) of the 
runner and transfers its kinetic energy to the bucket's wheel. The general formula of any hydro system is:

$\mathrm{P}=\eta \rho \mathrm{g} \mathrm{QH}$

Where:

$\mathrm{P}$ is the mechanical power produced at the turbine shaft (in Watts).

$\eta$ is the hydraulic efficiency of the turbine, $\rho$ is the density of water in $\left(1000 \mathrm{~kg} / \mathrm{m}^{3}\right)$.

$\mathrm{g}$ is the acceleration due to gravity in $\left(9.81 \mathrm{~m} / \mathrm{s}^{2}\right)$.

$\mathrm{Q}$ is the volume flow rate passing through the turbine in $\left(\mathrm{m}^{3} / \mathrm{s}\right)$.

$\mathrm{H}$ is the effective pressure head of water across the turbine in $(\mathrm{m})$.

For an impulse turbine of a Pelton-wheel type, the mechanical power can be changed by means of changing $\eta, Q$, and $H$ inputs because $\rho$ and $g$ are constant.

The force exerted by the water jet on buckets (vanes) of the runner in the direction of motion is given as:

$F x=\rho a V_{1}\left[V_{w_{1}}+V_{w_{2}}\right]$

Here,

$\rho=$ Density of the water.

$a=$ Cross section area of water-jet in $\mathrm{m}^{2}=\mathrm{p} / 4 \mathrm{~d}^{2}$,

$\mathrm{d}=$ diameter of jet in $\mathrm{m}$.

$V_{1}=$ Velocity of the jet at the inlet of bucket splitter,

$\mathrm{V}_{1}=\mathrm{v} 2 \mathrm{gH}$ in $\mathrm{m} / \mathrm{s}$.

$\mathrm{H}=$ Net head acting on the Pelton-wheel in $\mathrm{m}$.

$\mathrm{g}=$ Acceleration due to gravitation $\mathrm{m} / \mathrm{s}^{2}$.

$\mathrm{Vw}_{1}=$ Velocity of the whirl at inlet in $\mathrm{m} / \mathrm{s}$.

$\mathrm{Vw}_{2}=$ Velocity of the whirl at outlet in $\mathrm{m} / \mathrm{s}$.

The work done by the jet on the runner per second is as:

$\mathrm{W}_{\mathrm{j}}=\mathrm{F}_{\mathrm{x}} \times \mathrm{u}=\rho \mathrm{aV}_{1}\left[\mathrm{Vw}_{1}+\mathrm{Vw}_{2}\right] \times \mathrm{u} \mathrm{Nm} / \mathrm{s}$

Here,

$\mathrm{u}=$ Tangential linear velocity of the bucket wheel at pitch circle in $\mathrm{m} / \mathrm{s}$.

The energy supplied to the jet is in the form of kinetic energy which is given as $1 / 2 \mathrm{mv}^{2}$.

Now,

Kinetic Energy (K.E.) of the jet per second is given as:

$$
\text { K.E. }=1 / 2 \rho a V_{1} \times V_{1}^{2}
$$

Hydraulic Efficiency $\eta_{\mathrm{h}}=$ Work done by jet per second $\div$ K.E. of jet per second. $\rho_{\mathrm{h}}=\rho \mathrm{a} \mathrm{V}_{1}\left[\mathrm{Vw}_{1}+\mathrm{Vw}_{2}\right] \times \mathrm{u} \div 1 / 2 \rho \mathrm{a} \mathrm{V}_{1} \times \mathrm{V}_{1}^{2}$

In terms of $\mathrm{V}_{1}$

$\rho_{\mathrm{h}}=2\left(\mathrm{~V}_{1}-\mathrm{u}\right)[1+\cos \beta] \mathrm{u} \div 1 / 2 \rho a \mathrm{~V}_{1} \times \mathrm{V}_{1}^{2}$

$\left\{\mathrm{Vw}_{1}=\mathrm{V}_{1}-\mathrm{u}, \mathrm{Vw}_{2}=\left(\mathrm{V}_{1}-\mathrm{u}\right) \cos \mathrm{B}-\mathrm{u}\right\}$

For maximum efficiency $u$ is $=1 / 2 V_{1}$

$\eta_{\mathrm{hMax}}=1+\cos \beta / 2$

Here $\beta=$ Angle of Vane at outlet.

\section{Modified gravitational Pelton-wheel}

The modified gravitational Pelton-wheel turbine has been designed for a low-head and heavy-discharge application. In this turbine, buckets from a conventional Pelton-wheel have been modified by additional extra bucket-cups as shown in Figure 1. The bucket-cup is designed like a cattle-pot, where water pouring is done at the top opening and water discharge occurs at another opening somewhat similar to a tea cattle-pot.

The position and gap between two consecutive Pelton-wheel buckets and the additional bucket-cup on the runner is such that the water-jet axis does not interfere with conventional Pelton-wheel bucket central point, while striking on the modified bucketcup valve to store water. Similarly, it does not interfere with bucket-cup while striking on the conventional Pelton-wheel bucket. The bucket-cup's water storing action of jet takes place when the bucketcup reaches at P1 position of wheel. The bucketcup valve opens under the action of the jet strike and water gets stored in this bucket-cup. The dotted lines in insert 1 show the action of the jet on valve during filling of the bucket-cup. Inset 2 in Figure lexhibits a horizontal position for the bucket-cup when the valve is in a closed position and the bucket is filled with jet water.

Position P4 in the figure shows the jet discharge of bucket-cup's stored water. P5 is the position of wheel when the bucket-cup is fully empty. This turbine resembles a ferry-wheel where the $\mathrm{P} 1$ position of the bucket-cup wheel is near the potential Headrace at the opening of the nozzle jet exit. Position P1 where the kinetic energy of jet water is stored in the bucket-cup as gravitational potential energy.

$\mathrm{P} 5$ is the BDC position of the ferry-wheel just near P5, where the bucket-cup has become empty. Basically, the distance between potential Head-race $\mathrm{P} 1$ and P5 is the effective working diameter where jet water storage into the bucket-cup starts near nozzle exit and bucket-cup emptying finishes at P5. The bucket-cup pitch-circle-radius and Pelton-wheel bucket pitch-circle-radius is represented by ' $x$ ' and 'r' respectively, in Figure-1. Small ' $h$ ' is the effective 


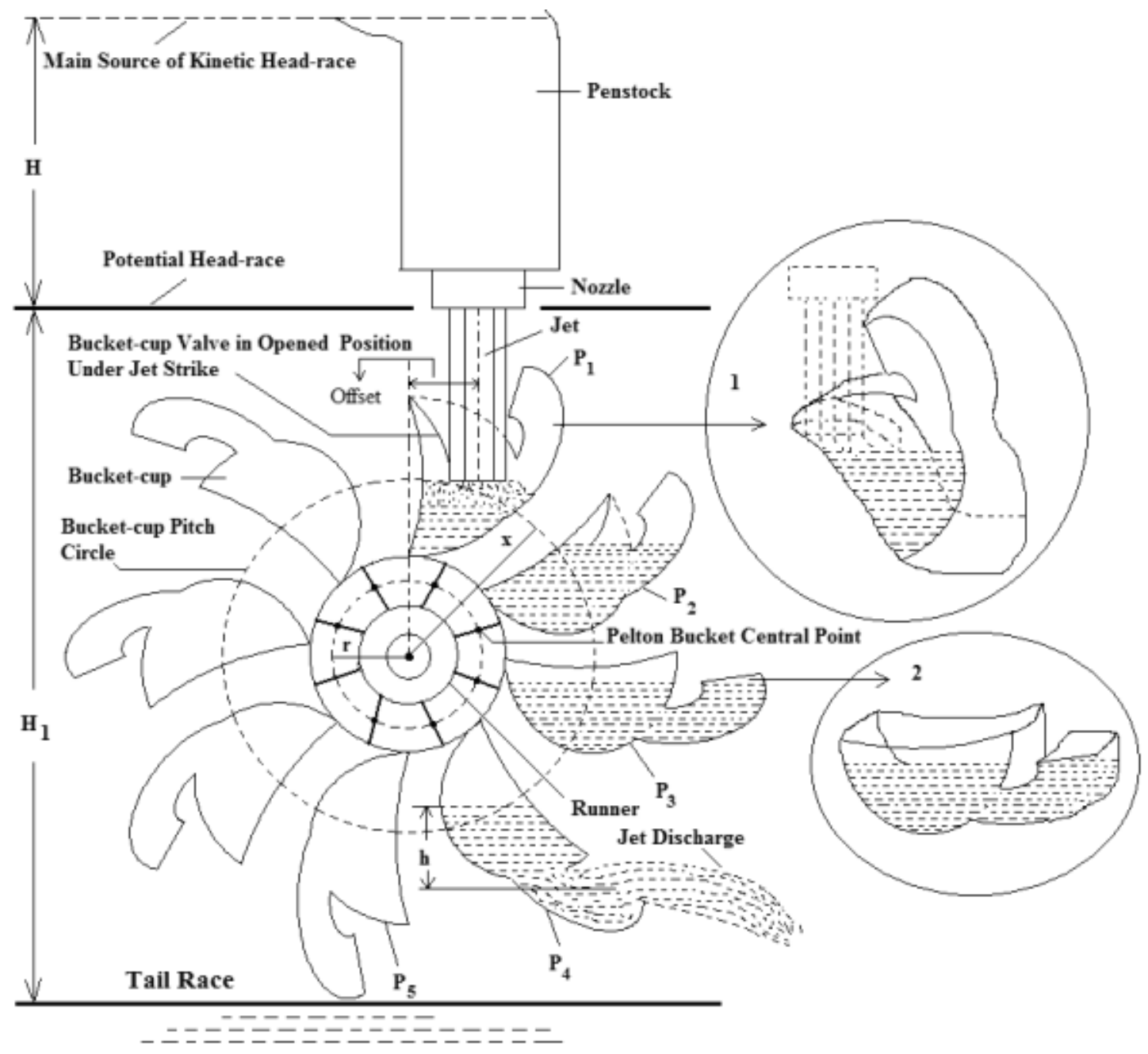

Figure 1: A modified gravitational Pelton-wheel

average head of stored water in the bucket-cup under which jet-propulsion take place.

\section{Working principle of a modified gravitational Pelton-wheel}

The modified gravitational Pelton-wheel is designed in such a way that it consumes the potential head $\mathrm{H} 1$ between P1 and P5 in the form of stored water weight in the bucket-cups. The kinetic head is consumed during the striking of the jet on bucket. The location and position of the additional bucket-cup on the conventional Pelton-wheel is such that it consumes jet water at P1. The weight of this stored water per second in the bucket-cup is the amount of potential energy per second from water jet. Further, this potential energy is converted into kinetic energy as this water filled bucket freely (assumed) falls during P1 to P5 position of the wheel.

It is also possible to extract kinetic energy from the penstock nozzle discharge by means of a jet strike on the conventional Pelton-wheel vanes of the runner. Figure 2 shows two cases of jet functions. Figure 2 (a) exhibits a position of jet and bucket-cup interaction when the jet strikes on the bucket-cup valve to facilitate adequate water filling. The dotted lines of the jet extension indicate behaviour of the jet on the Pelton-wheel vanes when the bucket-cup would has been absent. Figure 2 (b) shows the interaction of the jet with Pelton-wheel vanes, when it passes through the gap between two consecutive bucket-cups and results in a strike on the Peltonwheel vanes of the runner.

This hydro system is good for a low-head and heavy-discharge application. Apart from this, gravitational energy of stored water is further extracted during emptying of bucket-cup water by means of jet-propulsion under water head 'h', as shown by P4 position of bucket-cup in Figure 1. This jet propulsion works on a runner wheel taking place due to the Gravitational-Force on bucket-cup's stored water and results in a water jet discharge.

Stored water of bucket-cup enables delivery of two kinds of gravitational work on the runner wheel. Firstly, in the form of kinetic energy conversion during its under-gravity free falling and secondly in the form of jet-propulsion during its dis- 


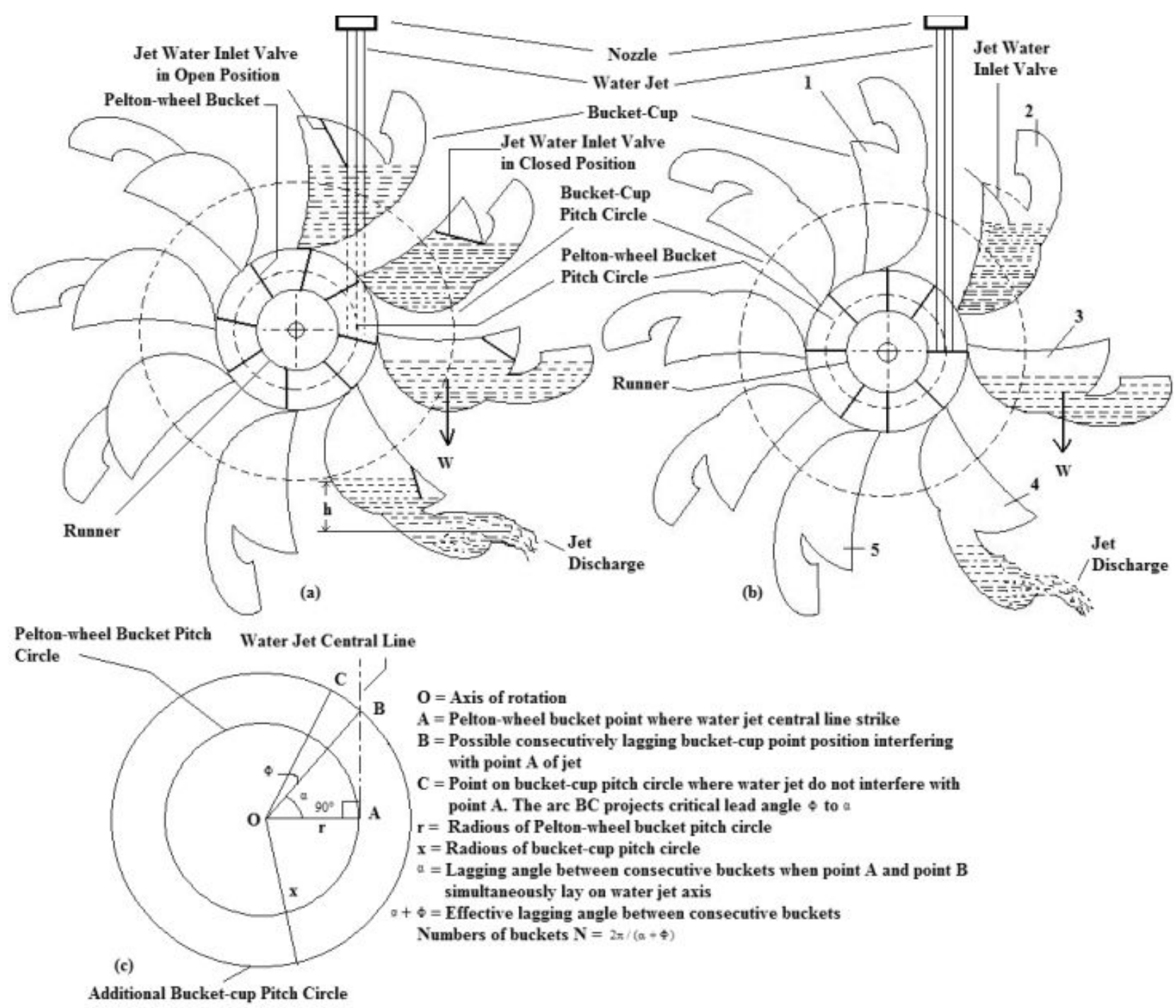

Figure 2: Two cases of jet functions

charge from bucket-cup under gravitational pulling. Further, there is a provision for jet impulse on vanes similar to the Pelton-wheel. Therefore, this hydro turbine has been named as a ModifiedGravitational-Pelton-wheel. This has been designed for running a comparatively bigger electrical generator than a conventional Pelton-wheel for a given low-head and heavy discharge application. Physically it is possible only in the case of a Modified-Gravitational-Pelton-wheel because of the presence of an additional gravitational impulse and momentum delivery from the available head. However, the problem of overbalancing the runner wheel due to one side of stored water can be a design challenge for engineers. But it can be controlled by proper mechanical balancing techniques which are beyond the scope of this paper.

\section{Runner work analysis of modified gravitational Pelton-wheel}

The foregoing descriptions cover various types of work which have been performed on a runner wheel by a main source of the water Head-race. The main potential head ' $\mathrm{H}$ ' is converted into a kinetic head at the penstock nozzle exit in the form of water-jet. The work performed by the hydraulic potential of the fluid reservoir is now discussed.

\section{A) Work of gravitational torque}

It has been observed that the water jet impact on buckets do not take place effectively in a conventional Pelton-wheel. This is because of the interference of one or more of the next lagging buckets which are behind the bucket of water jet action. There are instances when more than one bucket can be in the line of the water jet axis. The energy of water jet striking on these lagging buckets go to waste. This can be considered as a leakage loss and reduces the volumetric efficiency of the conventional Pelton-wheel.

The presence of lagging buckets cannot be ignored. In the modified version of the Pelton-wheel 


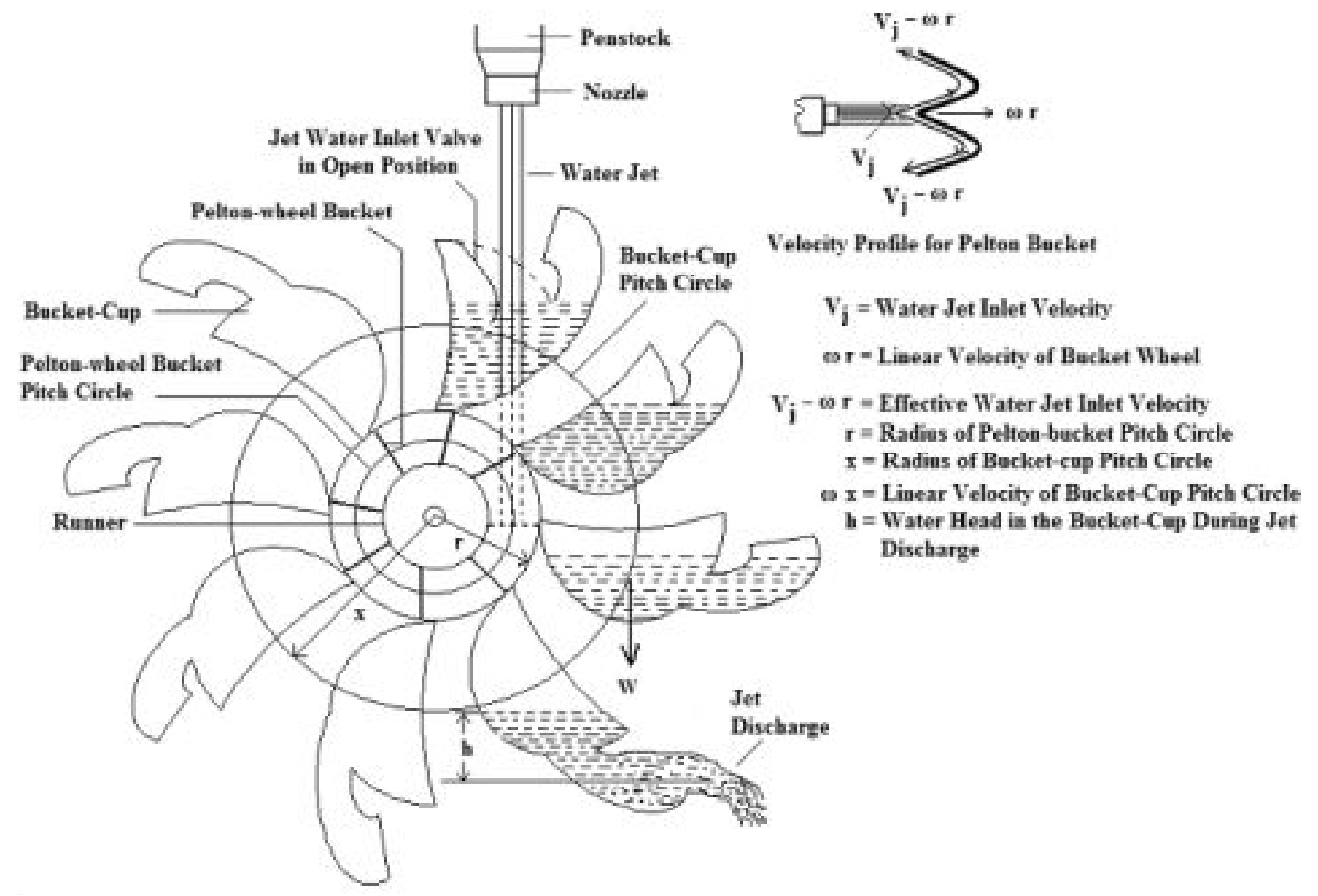

Figure 3: A modified gravitational Pelton-wheel bucket-cup and jet runner velocity profile

design, as shown in the Figure 3, the original buckets of the conventional Pelton-wheel have been extended to accommodate additional of cups at the end of the bucket. There is no change in the original convex splitter design of the Pelton-buckets. The dotted lines in Figure 3 represent a jet strike when the bucket-cup is not interfering with jet. Provisions of additional cups on the bottom rear end of the bucket enable storage space for jet water collection. However, the number of buckets can be reduced in such a way that there is no idle instant for the water jet.

A considerable quantity of jet water per second will be collected in the bucket-cup when the jet strikes on its valve. The actual strike of the water jet on the convex splitter of the Pelton-bucket is not affected by the presence of this additional bucketcup. No design modification is taken in Peltonbuckets.

It is possible to find two pitch circles on the Modified Gravitational Pelton-wheel. One pitch circle on the Pelton-buckets mid-line and another pitch circle on the bucket-cup's mid line. As per Figure 2 (c), the lagging angle between two consecutive buckets can be found for a given radius of the Pelton-bucket pitch circle radius $r$ and bucket-cup pitch circle radius $\mathrm{x}$. This lagging angle is shown as $\alpha$. The angle $\alpha$ between the two consecutive buckets indicates the positions of the Pelton-bucket and bucket-cup with reference to the water jet axis line.

At this angle for a given radius ' $r$ ' of the Peltonbucket pitch circle and a given radius ' $\mathrm{x}$ ' of bucket- cup pitch circle, the two points $\mathrm{A}$ and $\mathrm{B}$ of both the pitch circle simultaneously exist on the water jet centre line (water jet axis). The point $\mathrm{A}$ on the Pelton-bucket pitch circle enables a normal (perpendicular) strike of water jet on the Pelton-bucket (Figure $2 \mathrm{~b}$ ) and point $\mathrm{B}$ on the bucket-cup pitch circle enables an oblique strike of the water jet (Figure 2 a), which opens the valve to fill jet water into the bucket-cup.

Basically a is not suitable for proper functioning of the jet with the Pelton-bucket and bucket-cup because of the simultaneous interference of both the points $\mathrm{A}$ and $\mathrm{B}$ at the water jet axis. For proper functioning, this angle a should be little more than theoretical value of a which is given as a $=\cos -1$ $(\mathrm{r} / \mathrm{x})$ (see Figure $\mathrm{c}$ ). Angle $\mathrm{f}$ is arbitrary, which is chosen to get optimum utilization of water jet energy. The angle $(\mathrm{a}+\mathrm{f})$ between the two consecutive buckets is such that the water jet does not go idle for any moment. This angle $f$ provides an adequate position of both the Pelton-bucket and bucket-cup so that the jet freely acts to facilitate the bucket-cup water filling at one time and strikes on the Peltonvane at another time without any interference. This angle creates an offset between the jet axis and the runner-wheel axis, which in turn, always facilitates a torque on the runner-wheel in a clockwise direction only as shown in Figure 1. Therefore, the angle $\varphi$ is a critical angle which plays an important role in the design of a modified gravitational Pelton-wheel.

The stored water in the bucket-cup experiences a downward gravitational force. This force creates a 
torque on the runner wheel (see Figure 3). This force is acting at the pitch circle radius, i.e. at the centre of gravity (CG) of the cup. It is assumed that the water filled bucket-cup is behaving like a solid. The bucket-cup is moving with a constant angular velocity of $\omega \mathrm{x}$. Now, the relative velocity of the bucket-cup pitch circle with respect to the velocity of the water jet is obtained as:

$\mathrm{V}_{\mathrm{r}}=\mathrm{V}_{\mathrm{j}}-\omega \mathrm{x}$

(See Figure 3, difference between liner velocity of jet and bucket wheel).

This relative velocity $V_{r}$ is causing a supply of jet water into the bucket cup. The mass of jet water entering the cup per second is obtained as:

$M_{w}=\rho a V_{r}=\rho a\left(V_{j}-\omega x\right)$

( $a$ is cross sectional area of the jet)

Now, the weight of this water entering into the bucket cup per second is obtained as:

$W=M_{w} \times g=\rho a\left(V_{j}-\omega x\right) \times g$

This water of weight $\mathrm{W}$ in the bucket-cup generates a torque due to gravitation.

The torque $\mathrm{T}_{\mathrm{r}}$ developed by this weight $\mathrm{W}$ on the runner per second is obtained as:

$T_{r}=W \times x=\rho a\left(V_{j}-\omega x\right) g x$

The angular displacement $\theta$ of this torque in radian per second is equal to the angular velocity of the runner vanes i.e. $\omega$. If the linear velocity of the bucket-cup is $\mathrm{u}$ then $\mathrm{u}=\omega \mathrm{x}$, and $\omega=\mathrm{u} / \mathrm{x}=\theta[\theta$ $=$ Arc / Radius of pitch circle, here ' $u$ ' is assumed to be Arc]

Now, the work done by this torque $T_{r}$ on the runner wheel per second is obtained as:

$\mathrm{Wt}=$ Torque $\times$ angular displacement in radian per second

$\mathrm{W}_{\mathrm{t}}=\mathrm{T}_{\mathrm{r}} \times \theta$

$\mathrm{W}_{\mathrm{t}}=\rho \mathrm{a}\left(\mathrm{V}_{\mathrm{j}}-\omega \mathrm{x}\right) \mathrm{gx} \times \theta$

$\mathrm{W}_{\mathrm{t}}=\rho \mathrm{a}\left(\mathrm{V}_{\mathrm{j}}-\omega \mathrm{x}\right) \mathrm{gx} \times \mathrm{u} / \mathrm{x}$

$W_{t}=g \rho a\left(V_{j}-\omega x\right) u ~ N m / s e c o n d$

\section{Modelling of a gravitational torque work component}

The gravitational torque is an important parameter to be optimized for overall efficiency of a modified version of a Pelton-wheel. The analytical investigations reveal that the radius of a bucket-cup pitch circle diameter $x$ play an important role in the efficiency $\eta_{t}$ of torque work. Mathematically this efficiency is given by the development of the following expression: $\eta_{\mathrm{t}}=\left\{\mathrm{g} \times \pi\left(\mathrm{V}_{\mathrm{j}}-\mathrm{ux} / \mathrm{r}\right)\right\} /\left(\mathrm{V}_{\mathrm{j}}^{3}\right)$

A critical analysis of the above expression indicates that the value of the term $\left\{\left(\mathrm{V}_{\mathrm{j}}\right)-(\mathrm{u} \mathrm{x} / \mathrm{r})\right\}$ will become -Ve when term $\mathrm{u} x / \mathrm{r}$ becomes greater than $V_{j}$. In this situation, the efficiency term $\eta_{t}$ will become negative. For a given water head and wheel, radius $\mathrm{u}$ and $\mathrm{r}$ will be constant. Only $\mathrm{x}$ is the variable design parameter. This is vital information in the design of a modified Pelton-wheel. The value of $x$ at which efficiency $\eta_{t}$ becomes negative is a critical one from a design point of view. Because under such a condition, the wheel velocity $\mathrm{u}$ will become more than jet velocity $\mathrm{V}_{\mathrm{j}}$. In this condition, the jet will be unable to strike on the buckets and work done by the jet will stop till $\mathrm{u}$ reaches below $\mathrm{V}_{\mathrm{j}}$. Mathematically a relationship can be obtained for the maximum hydraulic efficiency $\eta_{t}$ for a given value of $\mathrm{x}$. This is obtained by applying differential rules of maxima for the above equation $\left(7.1^{*}\right)$ :

$\mathrm{d} \eta_{\mathrm{t}} / \mathrm{dx}=\mathrm{d} / \mathrm{dx}\left[\left\{\mathrm{g} \mathrm{x} \pi\left(\mathrm{V}_{\mathrm{j}}-\mathrm{ux} / \mathrm{r}\right)\right\} /\left\{\left(\mathrm{V}_{\mathrm{j}}^{3}\right)\right\}\right]$

$\mathrm{d} \eta_{\mathrm{t}} / \mathrm{dx}=\left\{\left(\mathrm{g} \pi / \mathrm{v}^{2}\right)\right\}-(2 \mathrm{x} \pi \mathrm{g} \mathrm{u}) /\left(\mathrm{r} \mathrm{V}_{\mathrm{j}}^{3}\right)$

Now, putting $d \eta_{t} / d x=0$

$\mathrm{x}=\left(\mathrm{r} \mathrm{V}_{\mathrm{j}}\right) /(2 \mathrm{u})$

Therefore, for maximum value of the hydraulic efficiency $\eta_{\mathrm{t}}$ the value of $\mathrm{x}$ is given as $\left(r \mathrm{~V}_{\mathrm{j}}\right) /(2 \mathrm{u})$. Now a mathematical expression for the maximum value of $\eta_{\mathrm{t}}$ can be obtained by substituting this value of $\mathrm{x}$ in the above equation (7.1*) and is obtained as:

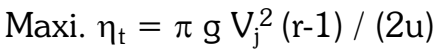

This mathematical model of the torque work component with respect to a bucket-cup pitch-circle radius $\mathrm{x}$ contributing hydraulic efficiency $\eta_{\mathrm{t}}$, is an essential part in the design of the modified version of a Pelton-wheel. This shall enable a guideline to the designer regarding the extraction of torque work from the kinetic energy of the main jet.

\section{B) Work of gravitational jet-propulsion}

In this modified version of the Pelton-wheel, the quantity of water stored in a bucket-cup is allowed to come out under gravity, through a mouth piece type orifice as shown in Figure 1. The bucket-cup position and design is such that it possesses a considerable water head ' $h$ ' as shown in the figure. This water head ' $h$ ' facilitates the removal of the stored water with absolute velocity $\mathrm{V}$ in such a way that the whole cup becomes empty just before the arrival of the bottom point P5 of the bucket's wheel.

The jet velocity of water coming out from the bucket-cup mouth piece produces a jet force, which is opposite to the direction of jet flow. This enables 
work on the runner vanes due to jet-propulsion from the bucket-cup discharge. The velocity of the runner wheel is $\mathrm{u}$. As the jet of water from the mouth piece exerts a force on the bucket-cup due to Newton's third law of reaction on action, the bucket-cup experiences a velocity vector $-\mathrm{u} 1$ opposite to the direction of the mouth piece jet velocity $\mathrm{V}$. This velocity vector bears a negative sign. Now the relative velocity $V_{r 1}$ of the mouth piece jet with respect to the bucket-cup is obtained as:

$\mathrm{V}_{\mathrm{r} 1}=$ Vector difference of absolute velocity of mouth piece jet $\mathrm{V}$ to the opposite velocity $-\mathrm{u}_{1}$ and vanes velocity $-\mathrm{u}$ (minus sign refers to opposite direction with respect to the absolute velocity $\mathrm{V}$ )

$\mathrm{V}_{\mathrm{r} 1}=\mathrm{V}-\left\{\left(-\mathrm{u}_{1}\right)+(-\mathrm{u})\right\}$

$\mathrm{V}_{\mathrm{r} 1}=\mathrm{V}+\mathrm{u}_{1}+\mathrm{u}$

Basically $V_{r 1}$ is the velocity of the mouth piece jet with which water comes out from the bucket-cup with respect to bucket-cup velocity $\mathrm{u}$.

Now, the mass of water coming out from the bucket-cup per second is obtained as:

$\mathrm{M}_{\mathrm{w} 1}=\rho \mathrm{a}_{1} \times$ velocity with which water comes out ( $a_{1}$ is cross sectional area of bucket-cup jet)

$\mathrm{Mw1}=\rho \mathrm{a}_{1} \times \mathrm{V}_{\mathrm{r} 1}$

$\mathrm{Mw1}=\rho \mathrm{a}_{1} \times \mathrm{V}+\mathrm{u}_{1}+\mathrm{u}$

The force Fy exerted on this water jet per second is designated by the rate of change in momentum. The initial velocity of water in the bucket cup is $u_{1}$ and the final velocity of the mouth piece water jet is $V_{r 1}$, Therefore force $F_{y}$ is obtained as:

$\mathrm{F}_{\mathrm{y}}=\mathrm{M}_{\mathrm{w} 1} \times\left(\mathrm{V}_{\mathrm{r} 1}-\mathrm{u}_{1}\right)$

$\mathrm{F}_{\mathrm{y}}=\mathrm{M}_{\mathrm{w} 1} \times\left(\mathrm{V}+\mathrm{u}_{1}+\mathrm{u}-\mathrm{u}_{1}\right)$

$\mathrm{F}_{\mathrm{y}}=\mathrm{M}_{\mathrm{w} 1} \times(\mathrm{V}+\mathrm{u})$

$\mathrm{F}_{\mathrm{y}}=\rho \mathrm{a}\left(\mathrm{V}+\mathrm{u}_{1}+\mathrm{u}\right) \times(\mathrm{V}+\mathrm{u})$

\{Subsituting value of $\mathrm{M}_{\mathrm{w} 1}$ \}

Fy is the force experienced by the mouth piece water jet because of gravitation and an equal amount of force in reverse to this applicable on the bucket-cup. The work done by this -Fy force on the bucket-cup i.e. on runner per second is due to jet propulsion and is obtained as:

$\mathrm{W}_{\mathrm{j}-\mathrm{p}}=-\mathrm{Fy} \times \mathrm{u}$

$\mathrm{W}_{\mathrm{j}-\mathrm{p}}=-\rho \mathrm{a}\left(\mathrm{V}+\mathrm{u}_{1}+\mathrm{u}\right) \times(\mathrm{V}+\mathrm{u}) \times \mathrm{u}$ Nm/second
(A minus sign indicates that the work is in opposite direction of jet flow i.e. force due to reaction)

\section{Selection of the number of buckets}

$\mathrm{S}_{1}$ is the arch length projected by angle $(\mathrm{a}+\mathrm{f})$ on the bucket-cup pitch circle of radius $\mathrm{x}$ (see Figure 2)

$S_{1}=(\alpha+\varphi) \times x$

Number of buckets $\mathrm{N}=2 \pi \times / \mathrm{S}_{1}$

$\mathrm{N}=2 \pi \mathrm{x} /(\alpha+\varphi) \times \mathrm{x}$

$\mathrm{N}=2 \pi /(\alpha+\varphi)$

\section{Energy analysis}

The total energy $E_{\text {total }}$ of the water jet per second with reference to the Tail-race level $\mathrm{H}_{1}$ is the algebraic sum of the kinetic energy of the water jet per second plus potential energy of the bucket-cup stored water per second and jet-propulsion work per second. This is given as:

$E_{\text {total }}=$ Kinetic energy of the jet $\left(\mathrm{W}_{\mathrm{j}}\right)$ per second + Potential energy of the jet $\left(\mathrm{W}_{\mathrm{t}}\right)$ per second + Jetpropulsion Work $\left(\mathrm{W}_{\mathrm{j}-\mathrm{p}}\right)$ per second.

$$
\begin{aligned}
& \mathrm{E}_{\text {total }}=\mathrm{K}+\mathrm{P} \\
& \mathrm{E}_{\text {total }}=1 / 2 \rho \mathrm{a} \mathrm{V}_{1} \times \mathrm{V}_{1}^{2}+\rho \mathrm{a} \mathrm{V}_{\mathrm{r}} \mathrm{gH}_{1}+ \\
& \rho \mathrm{a}\left(\mathrm{V}+\mathrm{u}_{1}+\mathrm{u}\right) \times(\mathrm{V}+\mathrm{u}) \times \mathrm{u} \\
& \mathrm{E}_{\text {total }}=1 / 2 \rho \mathrm{a} \mathrm{V}_{1} \times \mathrm{V}_{1}^{2}+\rho \mathrm{a}\left(\mathrm{V}_{\mathrm{j}}-\omega \mathrm{x}\right) \mathrm{g} \mathrm{H} \mathrm{H}_{1}+ \\
& \quad \rho \mathrm{a}\left(\mathrm{V}+\mathrm{u}_{1}+\mathrm{u}\right) \times(\mathrm{V}+\mathrm{u}) \times \mathrm{u} \\
& \quad\left\{\text { Because } \mathrm{V}_{\mathrm{r}}=\mathrm{V}_{\mathrm{j}}-\omega \mathrm{x}\right\}
\end{aligned}
$$

Here, $V_{1}$ is the velocity of water jet per second, $V_{r}$ is effective relative velocity of jet with respect to bucket wheel liner velocity and $\mathrm{H}_{1}$ is the height of water jet discharge between nozzle exit (TDC) and Tailrace (BDC) level. The hydraulic efficiency of the conventional Pelton-wheel is given as:

Hydraulic efficiency $\eta_{\mathrm{h}}=$ (Work done by jet/second $) \div($ K.E. of jet/second + P.E. of jet/second $)$

$$
\begin{aligned}
\eta_{\mathrm{h}}= & \rho \mathrm{a} \mathrm{V}_{1}\left[\mathrm{Vw}_{1}=\mathrm{Vw}_{2}\right] \times \mathrm{u} \div 1 / 2 \rho \mathrm{a} \mathrm{V}_{1} \times \mathrm{V}_{1}^{2} \\
& +\rho \mathrm{a}\left(\mathrm{V}_{\mathrm{j}}-\omega \mathrm{x}\right) \mathrm{g} \mathrm{H}_{1}
\end{aligned}
$$

Hydraulic efficiency of the modified gravitational Pelton-wheel is given as below:

Hydraulic efficiency $\eta_{\mathrm{h} 1}=$ (Work done by jet/second $) \div($ K.E. of jet/second + P.E. of jet/second $)$

$\eta_{\mathrm{h} 1}=\left[\left\{\right.\right.$ Kinetic work of jet/second $\left.\left(\mathrm{W}_{\mathrm{j}}\right)\right\}+$

$\{$ Gravitational work of bucket stored water/second $\left.\left(\mathrm{W}_{\mathrm{t}}\right)\right\}+\{$ Jet-propulasion work of bucket stored water/second $\left.\left.\left(\mathrm{W}_{\mathrm{j}-\mathrm{p}}\right)\right\}\right] \div[\{$ K.E. of jet/second + P.E. of Jet/second\}] 


$$
\begin{aligned}
\eta_{\mathrm{h} 1}= & {\left[\left\{\rho \mathrm{a} \mathrm{V}_{1}\left(\mathrm{~V} \mathrm{w}_{1}+\mathrm{V} \mathrm{w}_{2}\right) \times \mathrm{u}\right\}+\right.} \\
& \left\{\mathrm{g} \rho \mathrm{a}\left(\mathrm{V}_{\mathrm{j}}-\omega \mathrm{x}\right) \mathrm{u}\right\}+\left\{\rho \mathrm{a} V+\mathrm{u}_{1}+\mathrm{u}\right) \times \\
& (\mathrm{V}+\mathrm{u}) \times \mathrm{u}\}] \div\left[1 / 2 \rho \mathrm{a} \mathrm{V}_{1} \times\left(\mathrm{V}_{1}^{2}\right)\right\}+ \\
& \left.\left\{\rho \mathrm{a}\left(\mathrm{V}_{\mathrm{j}}-\omega \mathrm{x}\right) \mathrm{g} \mathrm{H}_{1}\right\}\right]
\end{aligned}
$$

In the modified version of the conventional Pelton-wheel discussed in this paper, the potential energy of the water jet is extracted in the bucket-cup stored water during its position at $(\mathrm{a}+\mathrm{f})$. This bucket-cup stored potential energy of the jet water continuously works on the runner in the form of $\mathrm{W}_{t}$ and $\mathrm{W}_{\mathrm{j}-\mathrm{p}}$ work on runner wheel till this bucket-cup reaches $\mathrm{P} 5$ position of the wheel with reference to the Tail-race level (see Figures 1, 2 and 3).

The energy balance for the conventional Peltonwheel and this modified version of the Pelton-wheel design is given as below:

\section{Energy in $\mathrm{E}_{\mathrm{I}}=$ Energy output $\mathrm{E}_{\mathrm{O}}+$ Energy loss $E_{L} \quad$ (12) (all the energy's per second)}

The amount of $E_{I}$ for both the conventional Peltonwheel and modified Pelton-wheel is the same.

EO for conventional Pelton wheel $=$ Work done by water jet on runner per second

$=\mathrm{Wj}$

$=2\left(\mathrm{~V}_{1}-\mathrm{u}\right)[1+\cos \mathrm{B}] \mathrm{u}$

EL for conventional Pelton-wheel $=$ Second law efficiency loss

$=$ Jet, air and vane surface friction loss + Fluid viscosity friction loss

Here, the Second law efficiency loss is common for both the turbines.

Now,

EO for the modified gravitational Pelton-wheel = Work done by water jet on runner per second

$\mathrm{E}_{\mathrm{O}}$ for modified gravitational Pelton-wheel $=\mathrm{W}_{\mathrm{j}}+$

$\mathrm{W}_{\mathrm{t}}+\mathrm{W}_{\mathrm{j}-\mathrm{p}}$

$E_{O}=2\left(V_{1}-u\right)(1=\cos \beta) u+g \rho a\left(V_{j}-\omega x\right) u+$

$\rho a\left(V+u_{1}+u\right) \times(V+u) \times u$

$\mathrm{E}_{\mathrm{L}}$ for the modified Pelton-wheel

$=$ Second law efficiency loss

$=$ Irreversitbility loss

$=$ Air friction loss + Viscosity friction loss

This energy analysis shows that energy extraction (hydraulic and volumetric) from the water jet of a given Tail-race level is greater for a modified gravitational Pelton-wheel than a conventional Peltonwheel.

\section{Torque and momentum analysis}

The runner shaft of a conventional Pelton-wheel does not get a continuous torque application during a water jet strike. This happens because of the gap between two consecutive buckets. Water jet's energy transfer to the runner wheel is nil during the idle time of the jet. However, in the case of a Modified Gravitational Pelton-wheel, a fixed value of torque continuously occurs on the runner wheel, because of the presence of the bucket-cup's stored water weight. This continuous torque enables smooth running of the runner shaft.

In a conventional Pelton-wheel, the momentum transfer between jet water and bucket vanes takes place only at a single point of jet strike on the bucket. The impulse of jet force is also limited and short in comparison to a Modified Gravitational Peltonwheel. The presence and rotary nature of the bucket-cup's stored water weight enables continuous momentum transfer with a long impulse on the runner wheel till it empties out at the Tail-race. According to the impulse-momentum theorem, the change in momentum of the runner wheel body equals the impulse of the net force, which occurs on the runner wheel during a presence period of the bucket-cup's stored water.

\section{A numerical based case study}

A case study of a conventional Pelton-wheel with assumed parameters has been carried out with respect to a modified version of a gravitational Pelton-wheel. The modified Pelton-wheel is assumed to be having the same parameters of the conventional Pelton-wheel. The numerical value of the hydraulic efficiency of the conventional Peltonwheel is obtained and is compared with the overall hydraulic efficiency of the modified version of the Gravitational Pelton-wheel.

Let us assume the following parameters which are applicable to a conventional Pelton-wheel:

Bucket diameter $=1 \mathrm{~m}$

Speed of wheel $\mathrm{N}=1000 \mathrm{rpm}$

Discharge $\mathrm{Q}=0.1 \mathrm{~m}^{3} / \mathrm{s}$

Tangential velocity of the wheel $\mathrm{u}=52.36 \mathrm{~m} / \mathrm{s}$

Side clearance angle $\beta=15$

Velocity of the jet $\mathrm{V}_{\mathrm{J}}=117.19 \mathrm{~m} / \mathrm{s}$

Co-efficient of velocity $\mathrm{C}_{\mathrm{v}}=1$

$\mathrm{a}=$ Cross section area of main water jet

a1 $=$ cross section area of bucket-cup discharge jet

Table 1 gives information about the hydraulic efficiency of conventional and modified versions of the Pelton-wheel. A modified version has same parameter as the conventional one except the values of $\mathrm{x}$ and $\mathrm{h}$. The term $\mathrm{x}$ and $\mathrm{h}$ are not valid in the case of conventional Pelton-wheel. The value of $\mathrm{x}$ and $\mathrm{h}$ are assumed as $1.5 \mathrm{~m}$ and $0.5 \mathrm{~m}$ respectively. 
The gain in the efficiency of the modified version is obtained as:

$$
\begin{aligned}
\eta_{\text {overall }} & =\eta_{\text {jet }}+\eta_{\mathrm{t}}+\eta_{\mathrm{j}-\mathrm{p}} \\
& =0.9718+0.0011+0.0056 \\
& =0.9785\left[\eta_{\mathrm{j}-\mathrm{p}} \text { when } \mathrm{a} 1=1 / 2 \mathrm{a}\right]
\end{aligned}
$$

The difference in the hydraulic efficiency of the Modified version with the conventional Peltonwheel is obtained as:

$$
\eta_{\text {difference }}=0.9785-0.9718=0.0067
$$

The percentage gain in the hydraulic efficiency of the modified version gravitational Pelton-wheel with regard to the conventional Pelton-wheel is obtained as:

Percentage gain $\eta_{\text {gain }}$

$=\eta_{\text {difference }} / \eta_{\text {jet }}$ conventional Pelton wheel $\times 100$

$=\{(0.9785-0.9718) /(0.9718)\} \times 100$

$=(0.0067 / 0.9718) \times 100$

$=0.00689 \times 100$

$=0.689 \%$

$=0.7 \%$ (approx.)

Again,

$$
\begin{gathered}
\eta_{\text {overall }}=0.9718+0.0011+0.0113=0.9842 \\
{\left[\eta_{\mathrm{j}-\mathrm{p}} \text { when a1 }=\mathrm{a}\right]}
\end{gathered}
$$

$\eta_{\text {difference }}=0.9842-0.9718=0.0124$

Percentage gain $\eta_{\text {gain }}=(0.0124 / 0.9718) \times 100$ $=1.275 \%$

The above results show that the net theoretical efficiency gain in the modified version is $0.7 \%$ more than the conventional Pelton-wheel. This efficiency gain is due to the modifications in the existing conventional Pelton-wheel, which enables more energy extraction from the available kinetic energy of the nozzle's fluid jet.

\section{Analysis of hydraulic efficiency due to jet-propulsion}

The expression $\eta_{\mathrm{j}-\mathrm{p}}=\{\rho \mathrm{a} 1 \times(\mathrm{Cv} \sqrt{ } 2 \mathrm{gh}+\mathrm{u}) \mathrm{Cv}$ $\sqrt{ } 2 \mathrm{gh} \times \mathrm{u}\} /\left\{1 / 2 \rho \mathrm{a} \mathrm{v} \mathrm{v}^{3}\right\}$ provides information about the two design parameters, which affect the hydraulic efficiency of the modified version of the gravitational Pelton-wheel. These parameters include a cross section area of the bucket-cup nozzle a1 and bucket-cup stored at water head $h$. Tables 2 and 3 give information about the hydraulic efficiency change due to the increase in the a1 and $\mathrm{h}$, respectively. The other parameters remain the same as discussed previously.

Table 2 shows that there is an increase in the efficiency of the jet-propulsion work with an increase in the cross section of the bucket-cup dis-

\begin{tabular}{|c|c|c|c|}
\hline S. No. & a1 in $m$. & $\eta_{j-p}=\{\rho a 1 \times(C v \sqrt{ } 2 g h+u) C v \sqrt{ } 2 g h \times u\} /\left\{1 / 2 \rho a^{\prime} v^{3}\right\} \times 100$ & $\% \square j-p$ \\
\hline 1. & $\mathrm{a} 1=0.5 \mathrm{a}^{\prime}$ & $\eta_{j-p}=\left\{\rho 1 / 2 a^{\prime} \times(C v \sqrt{2} g h+u) C v \sqrt{ } 2 g h \times u\right\} /\left\{1 / 2 \rho a^{\prime} v^{3}\right\} \times 100$ & 0.56 \\
\hline 2. & $\mathrm{a} 1=\mathrm{a}$ & $\eta_{\mathrm{j}-\mathrm{p}}=\left\{\rho \mathrm{a}^{\prime} \times(\mathrm{Cv} \sqrt{2 g h}+\mathrm{u}) \mathrm{Cv} \sqrt{2} \mathrm{gh} \times \mathrm{u}\right\} /\left\{1 / 2 \rho \mathrm{a}^{\prime} \mathrm{v}^{3}\right\} \times 100$ & 1.13 \\
\hline 3. & $\mathrm{a} 1=1.5 \mathrm{a}$ & $\eta_{j-p}=\left\{\rho 1.5 a^{\prime} \times(C v \sqrt{ } 2 g h+u) C v \sqrt{ } 2 g h \times u\right\} /\left\{1 / 2 \rho a^{\prime} v^{3}\right\} \times 100$ & 1.69 \\
\hline 4. & $\mathrm{a} 1=2 \mathrm{a}$ & $\eta_{j-p}=\left\{\rho 2 a^{\prime} \times(C v \sqrt{ } 2 g h+u) C v \sqrt{ } 2 g h \times u\right\} /\left\{1 / 2 \rho a^{\prime} v^{3}\right\} \times 100$ & 2.26 \\
\hline 5. & $\mathrm{a} 1=2.5 \mathrm{a}$ & $\eta_{j-p}=\left\{\rho 2.5 a^{\prime} \times(C v \sqrt{ } 2 g h+u) C v \sqrt{2 g h} \times u\right\} /\left\{1 / 2 \rho a^{\prime} v^{3}\right\} \times 100$ & 2.82 \\
\hline 6. & $\mathrm{a} 1=3 \mathrm{a}$ & $\eta_{\mathrm{j}-\mathrm{p}}=\left\{\rho 3 \mathrm{a}^{\prime} \times(\mathrm{Cv} \sqrt{2 g h}+\mathrm{u}) \mathrm{Cv} \sqrt{2} \mathrm{gh} \times \mathrm{u}\right\} /\left\{1 / 2 \rho \mathrm{a}^{\prime} \mathrm{v}^{3}\right\} \times 100$ & 3.39 \\
\hline 7. & $\mathrm{a} 1=3.5 \mathrm{a}$ & $\eta_{\mathrm{j}-\mathrm{p}}=\left\{\rho 3.5 \mathrm{a}^{\prime} \times(\mathrm{Cv} \sqrt{2} \mathrm{gh}+\mathrm{u}) \mathrm{Cv} \sqrt{2 g h} \times \mathrm{u}\right\} /\left\{1 / 2 \rho \mathrm{a}^{\prime} \mathrm{v}^{3}\right\} \times 100$ & 3.95 \\
\hline 8. & $\mathrm{a} 1=4 \mathrm{a}$ & $\eta_{j-p}=\left\{\rho 4 a^{\prime} \times(C v \sqrt{ } 2 g h+u) C v \sqrt{ } 2 g h \times u\right\} /\left\{1 / 2 \rho a^{\prime} v^{3}\right\} \times 100$ & 4.52 \\
\hline 9. & $\mathrm{a} 1=4.5 \mathrm{a}$ & $\eta_{j-p}=\left\{\rho 4.5 a^{\prime} \times(C v \sqrt{ } 2 g h+u) C v \sqrt{ } 2 g h \times u\right\} /\left\{1 / 2 \rho a^{\prime} v^{3}\right\} \times 100$ & 5.08 \\
\hline 10 . & $\mathrm{a} 1=5 \mathrm{a}$ & $\eta_{j-p}=\left\{\rho 5 a^{\prime} \times(C v \sqrt{ } 2 g h+u) C v \sqrt{ } 2 g h \times u\right\} /\left\{1 / 2 \rho a^{\prime} v^{3}\right\} \times 100$ & 5.65 \\
\hline
\end{tabular}
charge nozzle. The graphical presentation shown exhibits nearly a straight line. This indicates that the

Table 1: Hydraulic efficiency of conventional and modified versions of the Pelton-wheel

\begin{tabular}{llc}
\hline Hydraulic efficiency of system & Formula of hydraulic efficiency & Efficiency value \\
\hline$\eta_{\mathrm{jet}}$ Conventional Pelton-wheel & $2\left(\mathrm{~V}_{\mathrm{j}}-\mathrm{u}\right)(1+\cos \beta) \mathrm{u}$ & 0.9718 \\
\hline$\eta_{\mathrm{t}}$ Modified Version of Pelton-wheel & $\mathrm{g} \times \mathrm{p}\left(\mathrm{V}_{\mathrm{j}}-\mathrm{u} \times \mathrm{r}\right) /\left(\mathrm{V}_{\mathrm{j}}^{3}\right)$ & 0.0011 \\
\hline $\begin{array}{l}\eta_{\mathrm{j}-\mathrm{p}} \text { Modified Version of Pelton-wheel, } \\
\text { when } \mathrm{a} 1=\mathrm{a}\end{array}$ & $2 \mathrm{a} 1\{(\mathrm{Cv} \sqrt{ } 2 \mathrm{gh})+\mathrm{u})\}\{(\mathrm{Cv} \sqrt{2} \mathrm{gh} \times \mathrm{u})\} / \mathrm{a}\left(\mathrm{v}^{3}\right)$ & 0.0113 \\
\hline $\begin{array}{l}\eta_{\mathrm{j}-\mathrm{p}} \text { Modified Version of Pelton-wheel, } \\
\text { when } \mathrm{a} 1=1 / 2 \mathrm{a}\end{array}$ & $2 \mathrm{a} 1\{(\mathrm{Cv} \sqrt{ } \mathrm{g} \mathrm{gh})+\mathrm{u})\}\{(\mathrm{Cv} \sqrt{2} \mathrm{gh} \times \mathrm{u})\} / \mathrm{a}\left(\mathrm{v}^{3}\right)$ & 0.0056 \\
\hline
\end{tabular}

Table 2: Hydraulic efficiency change 
hydraulic efficiency is almost directional proportional to the a1.

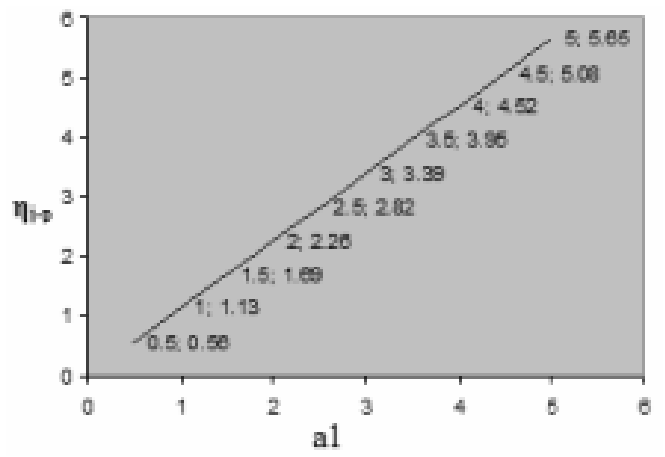

Table 3: Hydraulic efficiency change

\begin{tabular}{lll}
\hline S. No. & $h$ in $m$. & $\% \eta_{j-p}$ \\
\hline 1. & $\mathrm{~h}=0.5$ & 0.56 \\
\hline 2. & $\mathrm{~h}=1.0$ & 0.82 \\
\hline 3. & $\mathrm{~h}=1.5$ & 1.01 \\
\hline 4. & $\mathrm{~h}=2.0$ & 1.19 \\
\hline 5. & $\mathrm{~h}=2.5$ & 1.35 \\
\hline 6. & $\mathrm{~h}=3.0$ & 1.49 \\
\hline 7. & $\mathrm{~h}=3.5$ & 1.63 \\
\hline 8. & $\mathrm{~h}=4.0$ & 1.76 \\
\hline 9. & $\mathrm{~h}=4.5$ & 1.88 \\
\hline 10. & $\mathrm{~h}=5.0$ & 2.00 \\
\hline
\end{tabular}

From Table 3, it is clear that the jet-propulsion efficiency increases with an increase in the head of the stored fluid in the bucket-cup. The graphical presentation below also indicates that this relationship is not steep - instead it is showing a curve trend initially and approaches to nearly a straight value at $\mathrm{h}=3$.

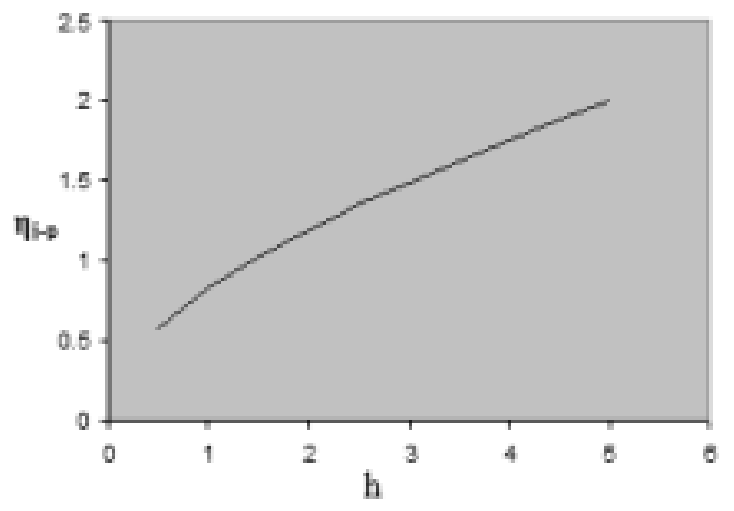

\section{Results and discussions}

A comparative analysis between a Modified Gravitational Pelton-wheel turbine and a conventional Pelton-wheel turbine working for the same water head will give following information:

1. The energy content of the runner shaft is lower in the conventional Pelton-wheel than the Modified version. This is because of the absence of additional gravitational work on the runner wheel due to $\mathrm{W}_{\mathrm{t}}$ and $\mathrm{W}_{\mathrm{j}-\mathrm{p}}$.

2. A Modified Gravitational Pelton-wheel is more effective for low-head and heavy discharge application. A Type-1 version of the gravitational Pelton-wheel is more suitable than the type-2 version because of the potential energy conversion point of view.

3. For the same head condition, heavy electrical generators can be used for designs of the Modified Gravitational Pelton-wheel than the conventional Pelton-wheel.

4. The proposed modified versions are very competent for mini and micro hydro power plants than conventional impulse and reaction turbines. In reaction turbines e.g. Francis, Kaplan etc., hydraulic irreversibility is comparatively more than of a Modified Gravitational Peltonwheel. The gravitational Pelton-wheel will be effective for very low-head (4 to 6 metres) and heavy discharge conditions.

5. The Design \& Development of a Modified Gravitational Pelton-wheel is simple because of the available fabrication techniques of welding. However, there is a problem of balancing because of the one-side overweighting, and is to be dealt with through proper bearing and supporting mechanisms like magnetic balancing etc.

6. The design and position of bucket-cups on the runner wheel should be such that it would collect the maximum possible jet water during its position at $(\mathrm{a}+\mathrm{f})$ and it must expel all of the stored water before just reaching P5 position at Tail-race.

7. The opening and closing of the bucket-cup valve (shown in Figure 1) for storing water head ' $h$ ' in the bucket-cup should facilitate effective inlet and outlet action of bucket-cup water. Actually the bucket-cup resembles functioning like teacattle where jet water enters at the top and comes out as a jet from the cattle pipe shape nozzle. The size of the nozzle should be adequate to facilitate fast discharge of all the stored water of the bucket-cup.

8. The hydraulic efficiency of the modified version of Pelton-wheel is obtained as:

Hydraulic efficiency $\eta_{\mathrm{h}}=\mathrm{W}_{\mathrm{j}}+\mathrm{W}_{\mathrm{t}}+\mathrm{W}_{\mathrm{j}-\mathrm{p}} \div$ K.E. + P.E. [Per Second]

\section{Concluding remarks}

The theoretical analysis and performance assessment of a Modified Gravitational Pelton-wheel indicates technologically excellent opportunities for hydro-mechanical conversion efficiency. The hydraulic irreversibility is low when energy conversion occurs from potential energy to kinetic energy by means of hydraulic mechanism as discussed in 
the proposed Modified Gravitational Pelton-wheel. The energy content of the runner shaft is lower in a conventional Pelton-wheel than the proposed Modified version.

This is because of the absence of additional gravitational work on the runner wheel due to $\mathrm{Wt}$ and Wj-p. A Modified Gravitational Pelton-wheel is more effective for low-head and heavy discharge applications. For the same head condition, heavy electrical generators can be used for a Modified Gravitational Pelton-wheel than a conventional Pelton-wheel.

\section{References}

Victor L. Streeter and E. Benjamin Wylie (1981), Fluid Mechanics, McGraw-Hill Book Company New York.

Irving H. Shames (1992), Mechanics of Fluids, McGrawHill International Edition.

Robert L. Daugherty, Joseph B. Franzini, E. John Finnemore (1989), Fluid Mechanics with Engineering Applications, McGraw-Hill Book Company, New York.

David Halliday, Robert Resnick and Jearl Walker (2004), Fundamental of Physics (Sixth Edition), John Wiley \& Sons, Inc., New York.

Hugh D. Young, and Roger A. Freedman (1998), University Physics (Ninth Edition), Addison Wesley Longman, Inc., New York, 1998.

R. K. Bansal (2002), Fluid Mechanics and Hydraulic Machines, Laxmi Publications, New Delhi.

Received 27 April 2009; revised 9 September 2009 